\title{
MIGRANTES HAITIANOS E BOLIVIANOS NA CIDADE DE SÃO PAULO: TRANSFORMAÇÕES ECONÔMICAS E TERRITORIALIDADES MIGRANTES
}

\author{
Haitian and Bolivian migrants in the city of São Paulo: \\ economic transformations and migrant territorialities
}

\author{
Luís Felipe Aires Magalhães* \\ Lúcia Maria Machado Bógus* \\ Rosana Baeninger ${ }^{* * *}$
}

\begin{abstract}
Resumo. Nos últimos anos, transformações na divisão internacional do trabalho têm promovido repercussões na dinâmica das migrações internacionais, como a emergência das migrações Sul Sul. Neste sentido, a cidade de São Paulo tem se consolidado como destino para muitos novos imigrantes internacionais e solicitantes de refúgio. Este artigo tem por objetivo analisar a inserção social de imigrantes haitianos e bolivianos em São Paulo. A metodologia contempla revisão teórica sobre migrações contemporâneas e território, bem como trabalho de campo de natureza qualitativa nos espaços sociais da capital paulista com maior presença de trabalhadores imigrantes destas nacionalidades.
\end{abstract}

Palavras-chave: migração internacional; imigração haitiana; imigração boliviana; território; São Paulo - SP.

\begin{abstract}
In recent years, changes in the international division of labor have caused repercussions on the dynamics of international migration, such as the emergence of South South migrations. In this sense, the city of São Paulo has become a destination for many new international immigrants and asylum seekers. This article aims to analyze the social insertion of Haitian and Bolivian immigrants in São Paulo. The methodology contemplates theoretical revision on contemporary migrations and territory, as well as field work of a qualitative nature in the social spaces of the city of São Paulo with a greater presence of immigrant workers of these nationalities.
\end{abstract}

Keywords: international immigration; Haitian immigration; Bolivian immigration; territory; São Paulo - SP.

\footnotetext{
* Pontifícia Universidade Católica de São Paulo (PUC - SP). São Paulo, SP, Brasil.

** Departamento de Sociologia da Pontifícia Universidade Católica de São Paulo. São Paulo, SP, Brasil.

*** Departamento de Demografia do IFCH- Universidade Estadual de Campinas. Campinas, SP, Brasil.
} 


\section{Introdução}

O processo histórico de conversão da cidade de São Paulo em espaço de valorização capitalista ${ }^{1}$ está diretamente associado ao crescimento da concentração urbana e à criação de novas territorialidades e centralidades. Exercendo múltiplos fatores de atração populacional desde a expansão da economia industrial, o processo de urbanização, não obstante ter alterado sua matriz econômica de industrial para de serviços, seguiu atraindo contingentes humanos, nacionais e internacionais, em processo de mobilidade.

A cidade de São Paulo passa, desde as últimas décadas do século XX, por um processo de reconversão econômica ${ }^{2}$, caracterizado por desconcentração industrial e crescimento de seu setor de serviços, que tem articulado novas mobilidades intra-urbanas, as quais fizeram crescer seu anel periférico ${ }^{3}$. Tem, também, atraído e absorvido um novo tipo de trabalhador imigrante internacional, não vinculado mais nem ao trabalho na indústria e tampouco ao trabalho na lavoura. Uma das principais faces dessa nova fase da migração internacional em São Paulo é a mobilidade de trabalhadores transnacionais de circuitos migratórios Sul-Sul, que encontram na cidade alocação em setores de baixa qualificação como costura, construção civil, limpeza pública e serviços domésticos. Seu processo de inserção laboral e ocupação do espaço é permeado pela produção de novas territorialidades, isto é, pela construção de espaços migrantes na cidade, destacados por práticas sociais, culturais e comerciais transnacionais ${ }^{4}$.

É sabido que essa nova migração internacional relaciona-se com o processo de periferização na cidade de São Paulo, seja pela valorização do espaço urbano, que desloca os migrantes para regiões mais afastadas, onde o custo da habitação é menor, seja por ações de fiscalização das relações de trabalho na costura, que levam as oficinas para distritos do anel periférico ${ }^{5}-$ levando com elas os migrantes ${ }^{6}$.

\footnotetext{
HARVEY, David. Cidades Rebeldes: Do direito à cidade à revolução urbana.

PASTERNAK, Suzana, BÓGUS, Lúcia. São Paulo: Transformações na Ordem Urbana.

PASTERNAK, Suzana. Evolução Espacial dos Loteamentos Irregulares em São Paulo.

4 Organização Internacional do Trabalho (OIT). Inserção Laboral de Imigrantes Internacionais: Transitando entre a economia formal e informal no município de São Paulo.

5 O anel periférico da cidade de São Paulo é formado por 36 distritos: Anhanguera, Artur Alvim, Brasilândia, Campo Grande, Campo Limpo, Capão Redondo, Cidade Dutra, Cidade Líder, Cidade Tiradentes, Ermelino Matarazzo, Grajaú, Guaianazes, Iguatemi, Itaim Paulista, Itaquera, Jaraguá, Jardim Ângela, Jardim Helena, Jardim São Luiz, José Bonifácio, Marsilac, Parelheiros, Parque do Carmo, Pedreira, Perus, Ponte Rasa, Raposo Tavares, Santo Amaro, São Mateus, São Miguel, São Rafael, Socorro, Vila Andrade, Vila Curuçá, Vila Jacuí e Lajeado. Sobre os anéis, ver: TASCHNER, Suzana Pasternak, BÓGUS, Lucia Maria Machado. A cidade dos anéis: São Paulo.

6 MAGALHÃES, Luís Felipe Aires, BÓGUS, Lúcia, BAENINGER, Rosana. Migrantes e Refugiados Sul - Sul na Cidade de São Paulo: Trabalho e espacialidades.
} 
Neste artigo, serão focalizadas as transformações recentes nos anéis central $^{7}$ e interior ${ }^{8}$, com importantes repercussões do ponto de vista da migração internacional e da produção do espaço urbano. Na análise, deteremos nossa reflexão no processo de produção de novas territorialidades de imigrantes haitianos e bolivianos em São Paulo, destacando a ocupação de espaços públicos em atividades culturais e comerciais.

\section{São Paulo: transformações socioespaciais e migrações contemporâneas}

O processo migratório, tanto interno como internacional, na cidade de São Paulo refere-se diretamente ao processo desigual de produção do espaço e de disputa pela cidade ${ }^{9}$. Em outras palavras, a migração é produto e produtora da forma com que se organiza o espaço urbano em São Paulo. Igualmente, o espaço - ou o local que os diferentes fluxos ocuparão no espaço - é um elemento diferenciador importantíssimo dos fluxos, apontando para seus distintos capitais sociais ${ }^{10}$ e econômicos - e suas distintas formas de produzir existência e território na cidade.

Convém destacar, no entanto, que essa cidade que recebe atualmente imigrantes e refugiados e os abriga sob diferentes contextos de segregação socioespacial, também ela foi produzida por distintos processos históricos de imigração ${ }^{11}$. Diversas pesquisas apontam a presença italiana, espanhola e portuguesa na cidade de São Paulo, além de outras nacionalidades, não tão expressivas do ponto de vista quantitativo, mas com enormes contribuições culturais, além da presença negra e da herança indígena que conformam o território multiétnico que configura a maior cidade do país. Esses contingentes populacionais foram essenciais para a constituição de um mercado de trabalho na cidade, com repercussões decisivas sobre a disponibilidade da força de trabalho e a estrutura do emprego ${ }^{12}$. Ao longo do processo de industrialização, as exigências da economia industrial e o aprofundamento das desigualdades regionais ativaram significativos fluxos migratórios internos, sobretudo do Nordeste e do estado de Minas Gerais, para a cidade de São Paulo ${ }^{13}$. Por sua

7 O anel central é formado por 6 distritos: Bela Vista, Consolação, Liberdade, República, Santa Cecília e Sé.

8 O anel interior é formado por 11 distritos: Barra Funda, Bom Retiro, Brás, Cambuci, Jardim Paulista, Mooca, Pari, Perdizes, Pinheiros e Vila Mariana.

9 PASTERNAK, BÓGUS, op. cit.

10 PACÍfICO, Andrea Maria Calazans Pacheco. O Capital Social dos Refugiados: Bagagem cultural versus políticas públicas.

11 VÉRAS, Maura Pardini Bicudo. DiverCidade: Territórios estrangeiros como topografia da alteridade em São Paulo.

12 BAENINGER, Rosana. Fases e faces da migração em São Paulo.

${ }^{13}$ SINGER, Paul. EConomia Política da Urbanização. 
vez, estes fluxos resultaram em aprofundamento da divisão social do trabalho e numa estratificação sócio-ocupacional ainda presente na cidade e na configuração territorial ${ }^{14}$.

Do ponto de vista do espaço, é importante destacar que as territorialidades migrantes são também historicamente datadas, no que distintos bairros da cidade, como Brás, Pari, Bom Retiro e Liberdade, são exemplos de espaços ocupados por diferentes nacionalidades em contextos sociais e econômicos variados. Há não apenas uma co-ocupação dos migrantes e refugiados nesses espaços, como também a expressão de uma trajetória intra-urbana, à medida em que migrantes e refugiados ascendem socialmente.

A cidade, com isso, cria e recria seus subalternos, abrigando-os em territórios determinados, espaços sociais urbanos marcados por estigmas e discriminações. Se o italiano deu lugar, em alguns bairros, a outras nacionalidades é por que novas hierarquias étnico-sociais foram produzidas a partir das transformações econômicas e urbanas na cidade.

O crescimento urbano de São Paulo e a ocupação crescente, de uma forma caracterizada por precariedade e segregação, tanto de seus anéis central e interior como de sua área periférica, é um processo geral que apresenta importantes especificidades temporais, desde os anos de $1940^{15}$.

Foi a partir de 1940 que se alterou significativamente o padrão de crescimento urbano em direção à periferia, deixando a cidade apta a um outro modelo de industrialização, aliás acelerada, que projetou novos centros fabris em vários pontos do município. É dessa época que o tripé loteamento de periferia, muitas vezes clandestino, casas próprias e autoconstrução configurou a extensão e a dispersão do espaço urbano. A cidade modificou-se, o sistema viário se expandiu, o transporte coletivo escolhido passou a ser o ônibus, os locais de trabalho se diversificaram e as alternativas habitacionais para os trabalhadores tornaram-se também variadas. A Lei do Inquilinato (1942), ao congelar os aluguéis, tornou o mercado pouco atraente para investimento dos proprietários. Dessa forma, a autoconstrução se intensifica e, especialmente após 1960 - quando se acentuam as migrações, dá-se grande aumento demográfico e a indústria automobilística exige novos investimentos no sistema viário -, a cidade assume cada vez mais o feitio de metrópole ${ }^{16}$.

Os referidos "novos pontos fabris" estão diretamente associados à produção de uma determinada morfologia urbana em regiões como Brás, Pari e Bom Retiro, que a reconversão econômica irá alterar. É a partir deste momento que se intensificará o processo de ocupação das áreas mais distantes

\footnotetext{
${ }^{14}$ PASTERNAK, BÓGUS, op. cit.

15 Ibidem.

${ }^{16}$ VÉRAS, Maura Pardini Bicudo. Novos Nômades Urbanos na Cidade Contemporânea: Desigualdade e exclusão sociais em São Paulo, p. 358-359.
} 
do centro urbano, isto é, seu anel periférico ${ }^{17}$. É importante considerar que, pelas características do controle e da posse de terras nas grandes cidades brasileiras, pelo caráter seletivo e elitista das políticas urbanas vigentes ao longo das últimas décadas e pela própria natureza vulnerável dos ocupantes, trata-se, fundamentalmente, de um processo de ocupação do solo marcado pela irregularidade fundiária ${ }^{18}$.

Esse processo foi levado a cabo também pelos imigrantes recém-chegados à cidade, em contexto de ausência tanto de políticas públicas específicas como de acesso à moradia em condições dignas e próxima ao centro urbano. Aqui, somam-se duas dimensões sociais historicamente caracterizadas por submissão do Estado às necessidades empresariais: a política urbana e a política imigratória.

Também a procura por áreas ainda não ocupadas se intensificou com o aumento da migração rural-urbana e a expansão do emprego industrial na metrópole de São Paulo, que estimulou a concentração urbana de famílias de baixa renda na periferia. Essa periferia cresceu, então, sem a intervenção do planejamento urbano, por meio de uma sucessão de loteamentos, muitos deles dito irregulares por não atenderem às legislações urbanas e ambientais vigentes ou irregulares por ocuparem lotes clandestinos, sem título de domínio ${ }^{19}$.

A permanência deste processo e a seletividade e elitismo das políticas urbanas e habitacionais, salvo articulações específicas importantes, mas incapazes de alterar a lógica da produção do espaço na cidade, têm promovido a distensão do tecido urbano em duas esferas absolutamente vinculadas do ponto de vista da dinâmica de reprodução do espaço urbano em seu sentido econômico, político e institucional: a cidade legal e a cidade ilegal. Essa contradição urbana vê-se agravada a partir da década de 1970, quando transformações econômicas internacionais impactam decisivamente na economia dependente brasileira, rompendo a vinculação até então existente entre mobilidade espacial (migração rural - urbana) e mobilidade social da população ${ }^{20}$. Essa ruptura está diretamente ligada ao processo de reconversão econômica.

Até meados da década de 70, a compra de um lote periférico e a autoconstrução permitiam o acesso à casa própria de grande parte dos trabalhadores paulistanos. E esses loteamentos, geralmente, eram implantados sem atender à legislação vigente. A redução dos salários, aliada ao aumento do preço da terra e às restrições legais da lei de Zoneamento de 1972, diminuiu a oferta de lotes no município de São Paulo, que cresceu nos demais municípios da Região Metropolitana. Os

\footnotetext{
17 PASTERNAK, op. cit.

18 Ibidem.

${ }^{19}$ BRUNA, Gilda Collet. Urbanização e Regularização de Loteamentos e Habitações, p. 369.

${ }^{20}$ BRITO, Fausto. As Migrações Internas no Brasil: Um ensaio sobre os desafios teóricos recentes.
} 
loteamentos irregulares foram um bom negócio imobiliário, aproveitandose da expansão e valorização da terra urbana. Mas, além de problemas ambientais e da dificuldade de extensão das redes de infraestrutura, a clandestinidade e a irregularidade impedem o registro e a obtenção de escritura pelos compradores ${ }^{21}$.

Como afirmado por Bruna ${ }^{22}$, o crescimento urbano da cidade de São Paulo promoveu a urbanização também das cidades da Região Metropolitana de São Paulo, sobretudo a partir de loteamentos irregulares.

Nas últimas décadas, no entanto, alterações importantes na ordem urbana têm acarretado uma diminuição do crescimento populacional na periferia de São Paulo e o retorno do crescimento populacional nos anéis central e interior. É evidente que o anel periférico segue tendo um peso importante para a cidade (em 2017, a população residente apenas neste anel representou 48,78\% da população total da capital paulista), inclusive crescendo acima da média do município (entre 2010 e 2017, a taxa de crescimento anual da população do anel periférico foi de 0,79\%, enquanto a do município foi de 0,56\%). Todavia, chama a atenção algumas alterações ocorridas para os anéis central e periférico. Para visualizá-las, apresentamos na Tabela 1 a taxa de crescimento anual da população residente nos diferentes anéis da cidade de São Paulo.

Tabela 1 - Taxas geométricas de crescimento anual da população de São Paulo segundo anéis (1960 - 2017)

\begin{tabular}{c|c|c|c|c|c|c}
\hline Anel & $\mathbf{1 9 6 0 - 7 0}$ & $\mathbf{1 9 7 0 - 8 0}$ & $\mathbf{1 9 8 0 - 9 1}$ & $\mathbf{1 9 9 1 - 0 0}$ & $\mathbf{2 0 0 0 - 1 0}$ & $\mathbf{2 0 1 0 - 1 7}$ \\
\hline Central & 0,69 & 2,23 & $-0,94$ & $-2,05$ & 1,24 & 0,60 \\
\hline Interior & 0,08 & 1,26 & $-1,17$ & $-1,78$ & 1,05 & 0,73 \\
\hline Intermediário & 2,79 & 1,28 & $-0,71$ & $-0,79$ & 0,81 & 0,39 \\
\hline Exterior & 5,52 & 3,13 & 0,83 & 0,13 & 0,33 & 0,24 \\
\hline Periferico & 12,81 & 7,39 & 3,05 & 2,71 & 0,96 & 0,79 \\
\hline Total & 4,79 & 3,66 & 1,13 & 0,92 & 0,76 & 0,56 \\
\hline
\end{tabular}

Fonte: IBGE: Censos Demográficos de 1960 a 2010; Estimativas Populacionais de 2017. Elaboração: próprios autores, 2017.

A principal alteração é que o anel central reverteu, na primeira década do século XXI, sua tendência de crescimento negativo, vigente desde a década de 1970. Isso indica um processo de reocupação do centro relacionado a um maior adensamento populacional nessa região, que nos faz refletir sobre a qualidade das moradias, e a um processo de expansão imobiliária, que nos remete à quantidade de moradias. Mesmo no auge do processo de crescimento urbano

\footnotetext{
21 PASTERNAK, op. cit., p. 414.

22 BRUNA, op. cit.
} 
em áreas de periferia da cidade, o centro sempre contou com uma quantidade significativa de imóveis desocupados e áreas ainda não construídas ${ }^{23}$.

Esse crescimento recente do anel central (que também ocorre, conforme a Tabela 1, no anel interior) do município de São Paulo está associado, como dito, a um maior adensamento populacional em muitos domicílios já existentes e a um crescimento da oferta de unidades habitacionais nos distritos que compõem estes anéis. Ao longo do século XX, muitos destes distritos alteraram sua morfologia urbana, deixando de ser regiões industriais para se converterem em bairros residenciais e, outras ainda, converteram-se nas últimas décadas em regiões de comércio popular, formal e informal. Essa nova matriz econômica, que produz sua própria espacialidade nesta região, altera também o perfil da mão de obra atraída e absorvida por essas relações de produção. É nesse contexto que se manifesta a presença haitiana e boliviana nos anéis central e interior do município de São Paulo.

\section{Novos Imigrantes em São Paulo}

Nos últimos anos, a mobilidade humana internacional tem apresentado uma importante característica: a predominância, tanto em termos migratórios como de refúgio, das migrações Sul-Sul ${ }^{24}$. Esse componente da mobilidade internacional se dá em decorrência de fatores como os entraves à imigração e ao refúgio nos países do Norte global, a manutenção e expansão de migrações intra-regionais em continentes como América Latina e Ásia e a emergência humanitária que caracterizam muitos solicitantes de refúgio em contextos como do Sudão do Sul, de Moçambique e da Guiné, que buscam refúgio nos países mais próximos.

O cenário das migrações internacionais no século XXI tem sido marcado por movimentos migratórios que incluem percursos, cada vez mais intensos, entre os países do Sul global. As restrições impostas pelos países do Norte para a entrada e permanência de migrantes internacionais consistem em importante elemento na reconfiguração das migrações e seus destinos no mundo hoje. As migrações Sul-Sul entre e em direção aos países da América Latina, na última década, demonstram a complexidade e heterogeneidade da imigração internacional. Denotam os desafios teórico-metodológicos para explicações e análises das migrações entre os países da região bem como da imigração haitiana, síria, africana, iraquiana, coreana, de imigrações qualificadas, de imigrações refugiadas, dentre outras modalidades migratórias que constroem o mosaico das tendências de deslocamentos de população na contemporaneidade. De fato, as migrações Sul-Sul se consolidam no bojo de processo mais amplo das migrações transnacionais, da divisão internacional do trabalho,

\footnotetext{
${ }^{23}$ PASTERNAK, op. cit.

${ }^{24}$ BAENINGER, Rosana. Migrações Sul-Sul.
} 
da mobilidade do capital. Refletem e (re)configuram condicionantes que ocorrem fora das fronteiras nacionais, com impactos na conformação da imigração no âmbito de cada país ${ }^{25}$.

Há de se considerar também os efeitos da crise econômica sobre as condições de trabalho dos imigrantes. A crise econômica que acometeu os países centrais do capitalismo global pós 2007/2008 promoveu uma deterioração das relações de trabalho que se abateu principalmente sobre a parcela do mundo do trabalho formada por trabalhadores imigrantes ${ }^{26}$. Consequentemente, agrava-se a discriminação a estes imigrantes ${ }^{27}$, diminuindo o volume de remessas de migrantes para os países de origem ${ }^{28}$ e fazendo emergir novas mobilidades da migração internacional ${ }^{29}$, com novas fases e faces da migração internacional ${ }^{30}$, tais como a migração de retorno e a reemigrarão ${ }^{31}$. Essas novas faces da migração reforçaram, como dito, a mobilidade Sul-Sul ${ }^{32}$.

A intensificação de instabilidades sociais e políticas, a emergência de conflitos armados e a perseguição a grupos étnicos, políticos, religiosos e culturais seguem produzindo movimentos de refugiados, aos quais também se impõem, como dito, as restrições crescentes à entrada na União Europeia e nos Estados Unidos. Nesse cenário, o Brasil tem se inserido também na dinâmica da mobilidade internacional de refúgio. A vinculação do Estado brasileiro aos tratados internacionais de refúgio e a Lei n. 9.474/1997 (Estatuto Jurídico do Refugiado) trouxeram também novos povos para o país, como os refugiados sírios, solicitantes de refúgio de diversos países da África e, ainda, os atuais solicitantes de refúgio venezuelanos ${ }^{33}$.

Em resumo, imigrantes de países como Haiti, Senegal e Gana, e refugiados sírios, angolanos, colombianos e congoleses ${ }^{34}$ integram o mosaico da imigração e do refúgio em São Paulo nos anos recentes. Essas novas chegadas se somam às outras anteriores, como a de peruanos, bolivianos e paraguaios, que seguem

${ }^{25}$ Ibidem, p. 13.

${ }^{26}$ CANALES, Alejandro. E Pur Si Muove. Elementos para una teoría de las migraciones en el capitalismo global; COVARRUBIAS, Humberto Márquez. Desarrollo y Migración: Una lectura desde la Economia Política.

${ }^{27}$ CANALES, op. cit.

${ }^{28}$ CEPAL. La actual crisis financiera internacional y sus efectos en América Latina y el Caribe; MAGALHÃES, Luís Felipe Aires. A imigração haitiana em Santa Catarina: perfil sociodemográfico do fluxo, contradições da inserção laboral e dependência de remessas no Haiti.

${ }^{29}$ BAENINGER, Rosana. Migração Transnacional: elementos teóricos para o debate.

30 BAENINGER, Fases e faces..., op. cit.

${ }^{31}$ FERNANDES, Duval, CASTRO, Maria da Consolação de. Migração e Crise: O retorno dos imigrantes brasileiros em Portugal.

32 BAENINGER, Migrações Sul-Sul, op. cit.

${ }^{33}$ SILVA, Camila Rodrigues da. Migração de Venezuelanos para São Paulo: Reflexões iniciais a partir de uma análise qualitativa.

${ }^{34}$ SINCRE - Sistema Nacional de Cadastro de Registro de Estrangeiro. Polícia Federal; BÓGUS, Lúcia Maria Machado, MOZINE, Viviane. Imigração e Refúgio no Brasil Contemporâneo: 1930-2012. 
aportando à cidade a partir de redes sociais já estabelecidas e presenças consolidadas em determinados segmentos do mundo do trabalho, ainda que precários.

A paisagem urbana e social de diversos bairros do município de São Paulo vê-se, assim, transformada com a chegada de novas nacionalidades e sua presença no comércio, na indústria da costura e em empreendimentos étnicos como os restaurantes e salões de beleza. Tal processo está em curso desde o final do século XX e se reforça neste século XXI, envolvendo, como vimos, de forma mais direta distritos da região central de São Paulo, como Bom Retiro, Liberdade, Pari, Brás, República e Sé.

A transformação urbana e social nesses distritos, por sua vez, guarda íntima relação com um processo anterior de desconcentração industrial, de expansão do setor terciário na cidade e dos processos atuais de reestruturação produtiva, onde São Paulo é o coração da indústria financeira do país ${ }^{35}$. A inserção laboral da população imigrante também se articula a estas transformações da produção global ${ }^{36}$.

Considerando a heterogeneidade dos processos sociais migratórios, sua distribuição espacial, sua concentração e as diferentes nacionalidades, a pesquisa qualitativa que dá suporta à reflexão teórica realizada nesse artigo considerou em seu arcabouço teórico-metodológico os seguintes pressupostos teóricos:

1) a heterogeneidade dos fluxos migratórios ${ }^{37}$;

2) a inserção diferenciada do imigrante no mercado de trabalho informal a partir das redes sociais ${ }^{38}$ e das relações de gênero ${ }^{39}$;

3) a formação de economia étnica ${ }^{40}$, com a conformação de nichos étnicos, onde também operam relações de gênero;

4) a formação e ocupação de espaços públicos, nos quais as manifestações culturais destes grupos imigrantes interagem socialmente, em atos e eventos em que as relações de gênero também estão presentes.

\footnotetext{
${ }^{35}$ PACHECO, Carlos Américo. Fragmentação da Nação

${ }^{36}$ SASSEN, Saskia. As cidades na economia mundial.

${ }^{37}$ CASTLES, Stephen, MILLER, Mark. The Age of Migration. International Population Movements in the Modern World.

${ }^{38}$ GUARNIZO, Luis Eduardo et alii. Assimilation and Transnationalism: Determinants of Transnational Political Action among Contemporary Migrants.

${ }^{39}$ PERES, Roberta. Imigração e Gênero: As mulheres haitianas no Brasil.

${ }^{40}$ BONACICH, Edna. A Theory Of Ethnic Antagonism. The Split Labor Market; WALDINGER, Roger. The Ethnic Enclave Debate Revisited; PORTES, Alejandro, LANDOLT, Patricia. The downside of social capital.
} 


\section{Imigração haitiana}

A imigração haitiana no Brasil é um fenômeno social que, embora recente (os primeiros registros desta presença no país são do final de 2010), insere-se em um contexto de diversos processos históricos de emigração (Cuba, República Dominicana, Estados Unidos, Canadá, França e Bahamas) que, desde meados do século XIX, têm produzido no Haiti uma tradição migrante ${ }^{41}$. No Brasil, pelo menos 85 mil haitianos e haitianas tiveram no país local de destino ou de trânsito, ressaltando a existência de estratégias migratórias internas no Brasil e mesmo para outros países ${ }^{42}$. Em que pese um perfil social e demográfico inicial caracterizados por chegada indocumentada ao Brasil e condições muito precárias de acolhimento na fronteira do Brasil com o Peru, atualmente esse perfil tem se alterado, especialmente por efeito das Resoluções Normativas 97 e 102 do CNlg, que operam, via expansão da emissão de vistos no Brasil, no Haiti e em outros países (Peru, Equador, Bolívia e República Dominicana), a mudança na migração de uma via terrestre para a via aérea ${ }^{43}$.

Em São Paulo, os imigrantes haitianos são admitidos sobretudo nos setores da construção civil (serventes de obra) e de alimentação e restaurantes. As mulheres haitianas ocupam predominantemente postos de cozinheiras em restaurantes e faxineiras em estabelecimentos terciários ${ }^{44}$. São elas as maiores responsáveis por dois fenômenos sociais característicos da migração haitiana em São Paulo: a formação de um território étnico a partir de sua concentração em um espaço público físico apropriado e vivido ${ }^{45}$ e as manifestações, nestes espaços, de práticas transnacionais ${ }^{46}$. O principal desses espaços é a Baixada do Glicério.

Na Baixada do Glicério, região limite entre os distritos da Liberdade e da Sé (anel central da cidade), a apropriação do espaço público por haitianos e haitianas dá-se em decorrência da presença no local da Missão Paz, principal espaço de acolhimento de imigrantes na cidade e no país.

Ao redor da Missão Paz, a paisagem urbana e social vê-se, desde 2010, redesenhada, predominando atualmente população imigrante haitiana ${ }^{47}$. Espaços como a rua dos Estudantes, rua Conde de Sarzedas, rua do Glicério e rua Dr. Lund apresentam intensa atividade comercial de negócios típicos da comunidade haitiana, como pequenas lojas de envio de remessas de migrantes, barbearias, salões de beleza, lojas de conserto de bicicletas e restaurantes. $\mathrm{Na}$

\footnotetext{
${ }^{41}$ MAGALHÃES, op. cit.; BAENINGER, Migração Transnacional..., op. cit.

${ }^{42}$ MAGALHÃES, BÓGUS, BAENINGER, op. cit.

${ }^{43}$ MAGALHÃES, op. cit.

${ }^{44}$ MAGALHÃES, BÓGUS, BAENINGER, op. cit.

${ }^{45}$ BOURDIEU, Pierre. Efeitos do Lugar. A miséria do mundo.

${ }^{46}$ CANALES, op. cit.

${ }^{47}$ MAGALHÃES, BÓGUS, BAENINGER, op. cit.
} 
rua Glicério, por exemplo, há um bar haitiano que serve comida e bebida típicas do país, com ensaios abertos, aos sábados, da banda Satellite Musique, formada por músicos haitianos. Ao lado de uma ocupação urbana, o bar reúne imigrantes haitianos e opera como um espaço de sociabilidade e de construção de uma territorialidade migrante no Glicério.

A formação desse espaço público identitário haitiano é, também, decorrência do enorme adensamento domiciliar: a existência nessa região de cortiços e de casas coabitadas faz das calçadas o espaço de convivência, dado que as casas são, muitas vezes, utilizadas exclusivamente para o descanso e repouso. Na rua do Glicério, onde se situa a Missão Paz, é onde essa presença haitiana é mais visível, e nela as "Madanm Sara" mostram a face mais evidente do caráter transnacional dessa mobilidade. Por "Madanm Sara" são chamadas as mulheres haitianas que preparam e comercializam alimentos e refeições em Porto Príncipe e em todo o Haiti. São elas quem fornecem, em um contexto de escassez de restaurantes e insegurança alimentar, a alimentação diária da maior parte das famílias haitianas. Segundo Thomaz ${ }^{48}$, "as Madanm Sara são as comerciantes que garantem a oferta de produtos de boa parte dos mercados de Porto Príncipe. Conectam a capital com as regiões rurais do país e são as responsáveis até mesmo por circuitos existentes entre o Haiti e a República Dominicana, os Estados Unidos e o Panamá" ${ }^{49}$. Não seria forçoso já incluir o Brasil e especificamente São Paulo no rol dessa conexão, ou, em outras palavras, no "espaço de vida" ${ }^{50}$ da migração haitiana ${ }^{51}$. A capilaridade das "Madanm Sara" no território das cidades haitianas é tão grande que, no pós-Terremoto de 2010, quando a Minustah não sabia precisamente como fazer levar os alimentos e medicamentos arrecadados mundialmente, foram elas que aliviaram, com seus produtos e sem qualquer procura e reconhecimento da Minustah, a situação de enorme vulnerabilidade na região da capital $^{52}$.

Ao redor da Missão Paz, essas mesmas "Madanm Sara" resignificam o território social da Baixada da Glicério e alteram a paisagem urbana da região: bananas da terra são fritas e cozidas em panelas enormes, espigas de milho são assadas em latões improvisados, doces de farinha e de coco preparados e vendidos nas calçadas, assim como "cremas", bebida típica haitiana, e outras frutas. Nada disso havia antes da presença haitiana na região. As "Madanm Sara", juntamente com todo o conjunto de negócios étnicos haitianos da região, mostram a vitalidade e importância da ação das mulheres para a reprodução

\footnotetext{
48 THOMAZ, Omar Ribeiro. O terremoto no Haiti, o mundo dos brancos e o lougawou.

${ }^{49}$ Ibidem, p. 30.

${ }^{50}$ COURGEAU, Daniel. Nuevos Enfoques para Medir la Movilidad Espacial Interna de la Poblácion; DOMENACH, Hervé. Sobre la "Migratología".

${ }^{51}$ MAGALHÃES, op. cit.

52 THOMAZ, op. cit.
} 
social da comunidade haitiana - manutenção de seus códigos étnico-nacionais e negociação de sua presença no território.

Em que pese a importância da presença feminina na imigração haitiana em São Paulo, a participação das mulheres haitianas nas atividades culturais e políticas da comunidade não é frequente. A associação dos haitianos da cidade é bastante masculinizada, o que expressa uma relação de gênero em que às mulheres historicamente outras tarefas são atribuídas. Assim parece ser na associação de São Paulo, de outras cidades em outros estados do Brasil, e na própria capital haitiana, Porto Príncipe ${ }^{53}$.

\section{Imigração boliviana}

O fluxo e a comunidade boliviana em São Paulo, por serem já estabelecidos (remontam a meados do século XX), possuem outras características e outras formas de inserção laboral, construção de território, apropriação de espaços públicos e participação e organização cultural e política.

No que se refere ao histórico da presença boliviana na cidade, Silva ${ }^{54}$ ressalta que

a presença boliviana em São Paulo não constitui um fato novo. Embora ela tenha se tornado significativa somente a partir da década de 1980, pode-se dizer, contudo, que tal presença remonta ao início da década de 1950, quando já era possível constatar alguns bolivianos na cidade na condição de estudantes, os quais vieram estimulados pelo programa de intercâmbio cultural Brasil-Bolívia. Após o término dos estudos, muitos deles acabavam optando pela sua permanência na cidade, em razão das múltiplas ofertas de emprego encontradas naquele momento no mercado de trabalho paulistano. As razões pelas quais os bolivianos continuam deixando a Bolívia são múltiplas. Porém, os fatores de ordem econômica são preponderantes na decisão de emigrar, já que o mercado de trabalho brasileiro, mesmo na denominada "década perdida", ou seja, a de 1980, oferecia mais oportunidades de emprego do que o mercado de trabalho boliviano, já que o país enfrentava uma profunda crise econômica, com altos índices de inflação e desemprego ${ }^{55}$.

A imigração boliviana em São Paulo concentra-se atualmente nos setores da costura e venda de produção têxtil nos bairros do Brás, Pari e Bom Retiro, distritos do anel interior do município de São Paulo. Nesses distritos, dividem o território com outros imigrantes latino-americanos (peruanos e paraguaios), africanos (senegaleses e ganeses, principalmente) e asiáticos (chineses e sul-coreanos). As interações sociais entre esses grupos migrantes restringem-se às relações de trabalho: paraguaios, peruanos e bolivianos produzem as roupas

\footnotetext{
${ }^{53}$ MAGALHÃES, op. cit.

${ }^{54}$ SILVA, Sidney Antônio da. Bolivianos em São Paulo: entre o sonho e a realidade.

55 Ibidem, p.159-160.
} 
contratados por empresas de chineses e sul-coreanos que funcionam em prédios pertencentes à comunidade árabe; as roupas são vendidas também por senegaleses e ganeses, formal e informalmente, na extensão das ruas Rangel Pestana e Celso Garcia. Na costura, homens e mulheres dividem oficinas caracterizadas por insalubridade do ar, intensa atividade laboral, longas jornadas e sistemas diferenciados de remuneração. Embora seja um fluxo mais antigo, em trabalhos de campo anteriores pudemos concluir que sua manutenção é essencial para o funcionamento das relações de dominação econômica no trabalho: atualmente, as redes de contratação operam desde a Bolívia, recrutando pessoas que já realizavam o trabalho na costura. A viagem ao Brasil e a primeira residência criam uma dívida do trabalhador com o seu recrutador (frequentemente um amigo ou alguém conhecido e próspero na comunidade, também ela transnacional, não obstante ser um país vizinho) e um laço de dependência que impede a saída do trabalho da costura.

A lei que rege a relação entre empregadores e trabalhadores dentro do mesmo grupo é a da fidelidade étnica, a qual quando é rompida pelo trabalhador o seu empregador passa a exigir do mesmo todos os gastos que este teve para trazê-lo a São Paulo e em alguns casos, o intimida com ameaças. Nos casos em que a inda do trabalhador é financiada, este assume uma dívida real e ao mesmo tempo moral com o seu empregador, em geral um compatriota, o qual passará a exigir do mesmo fidelidade, pelo menos por um ano. Além de financiar a viagem, o empregador fornece também casa e alimentação, criando assim (...) uma íntima relação entre a dádiva paternalista e as obrigações criadas pelo endividamento simbólico. Neste sentido (...), 'a dádiva que não é restituída pode se tornar uma dívida, uma obrigação durável e o único poder reconhecido - consubstanciado'. Cria-se, dessa forma, um forte controle sobre esta mão-de-obra, a qual se utiliza da estratégia da rotatividade no emprego para tentar romper esse esquema de reações trabalhistas profundamente perverso ${ }^{56}$.

O sistema de pagamento depende diretamente da condição do trabalho: se informal, depende do número de peças produzidas (geralmente é pago $\mathrm{R} \$ 1,50$ por camisa e $\mathrm{R} \$ 2,00$ por peças maiores) ou mesmo do número de costuras realizadas ( $R \$ 0,25$ por parte da peça costurada). As jornadas de trabalho nesse caso costumam ser de 12 horas por dia ou mesmo mais. É na informalidade em que ocorre a residência na própria oficina, e isso é fundamental, como veremos a seguir, no âmbito das estratégias específicas construídas pelas trabalhadoras bolivianas. Se formal, a jornada oscila entre 40 e 50 horas semanais, com uma remuneração fixa de um salário mínimo mais prêmios por produtividade, vale transporte e vale alimentação. O controle do tempo é tão importante que as jornadas incluem frações de hora, sendo, predominantemente, das $07 \mathrm{~h}$ às

\footnotetext{
${ }^{56}$ SILVA, Sidney Antônio da. Uma Face Desconhecida da Metrópole: Os bolivianos em São Paulo,
} p. 16. 
16h48. Aos sábados, o trabalho é até as $12 \mathrm{~h}$, quando a partir de então abre-se a esses bairros uma intensa apropriação do espaço e construção, comercial e cultural, do território.

É importante observar que a informalidade do trabalho em nichos caracterizados por integrar cadeias mercantis de valor com presença de marcas e capital internacional mais que a expressão de uma deterioração local do trabalho é também uma consequência do novo padrão de acumulação em escala global.

A precarização do trabalho no contexto atual do capitalismo e na nova estrutura de organização da produção em cadeias produtiva, com níveis de subcontratação e terceirização, tem conduzido ao entendimento de novas feições da informalidade. Castel (1998) denomina de "a nova questão social", a qual é engendrada por transformações na dinâmica produtiva e não mais fenômeno marginal a ser superado pelo progresso. A precarização do emprego e o desemprego se inseriram na dinâmica atual da modernização, através das reestruturações e competitividade industriais. No cenário dos novos processos de precarização do trabalho e os novos fluxos migratórios, as cadeias produtivas em âmbito global contribuem para a expansão da economia informal. No bojo desse novo processo de informalidade, os novos fluxos migratórios internacionais constituem a formação de um excedente migrante no mercado de trabalho mundial ${ }^{57}$.

Formalidade e informalidade não são, neste contexto, excludentes. Seja do ponto de vista econômico, em que etapas informais somam-se até uma última etapa formal de comercialização, sob a qual o setor integra uma cadeia mercantil de valor que alimenta a acumulação comercial inclusive em outras regiões do país, seja do ponto de vista das relações de gênero, em que as mulheres tornam-se mais comuns na informalidade justamente pelas exigências da jornada de trabalho doméstico: o cuidado com as crianças é central para aquelas que escolhem residir nas oficinas e ter, com isso, seus filhos e filhas diante dos olhos.

A partir das $12 \mathrm{~h}$ de sábado até a noite de domingo, a comunidade boliviana busca ocupar os espaços públicos da região e fortalecer seus laços de solidariedade étnica. Dois espaços são mais ocupados, cada um a seu modo. Culturalmente, a Praça da Kantuta, na região do Canindé, bairro do Pari, reúne centenas de bolivianos e bolivianas. É nela em que ocorre a tradicional "Feira da Kantuta", em que todos os domingos, das 11h às 19h, o mosaico gastronômico, artesanal e cultural da Bolívia é apresentado e reverenciado. Comercialmente, é a rua Coimbra, no Bairro do Brás, em que o espaço público é mais apropriado e utilizado. Em sua extensão, inúmeros restaurantes, casas de câmbio, lojas de envio de remessas, agências de companhias aéreas, salões de beleza e mesmo

${ }^{57}$ OIT, op. cit., p. 20. 
mercados étnicos, nos quais são vendidas batatas, milhos, frutas e cervejas, produzidas na Bolívia e transportadas em pequenos caminhões até São Paulo.

$\mathrm{Na}$ apropriação comercial do espaço, as mulheres ocupam, além do trabalho nas oficinas, trabalhos nos salões de beleza e na alimentação de calçada (nos restaurantes, formalizados, elas são raras). O trabalho nos salões revela uma divisão dos rendimentos totais que se assemelha ao trabalho nas oficinas de costura: as trabalhadoras informais residem no andar superior do salão e recebem $50 \%$ do valor de cada corte. O restante é do empregador, que paga o aluguel do espaço a proprietários que, segundo as entrevistadas, também são árabes. Em alguns casos, foram esses empregadores que tiveram que autorizar ou não as entrevistas de suas funcionárias. As mulheres, em termos gerais, são menos predominantes nos estabelecimentos da rua Coimbra. Mas é no final desta rua, no Centro Integrado do Imigrante, em que as mulheres são mais visíveis, seja como funcionárias do Centro, seja como demandantes de seus serviços de qualificação profissional, assistência médica e encaminhamento a órgão da prefeitura.

O descanso do trabalho nas oficinas se dá nas feiras culturais, mas mesmo nessas as mulheres, bem mais que os homens, comercializam bens que conseguiram produzir em suas máquinas de costura próprias, comidas e artesanatos. "Descansam" trabalhando um pouco mais, perfazendo dessa forma uma tripla jornada de trabalho.

Na apropriação cultural do espaço, cabe destacar que a Feira da Kantuta ocorre no âmbito de uma intensa e organizada mobilização cultural. A comunidade boliviana em São Paulo possui não apenas uma Associação dos Residentes Bolivianos (que existe há 47 anos e está localizada no próprio Centro Integrado do Imigrante) como também a Associação Cultural Folclórica Bolívia Brasil, cuja missão é "promover a diversidade cultural e de valores religiosos que identificam o povo boliviano com suas tradições e raízes para futuras gerações" 58 . Localizada no Canindé, mais próxima de onde ocorre a Feira da Kantuta, a Associação organiza festividades como a Festa da Independência da Bolívia (que geralmente ocorre no Memorial da América Latina, no primeiro final de semana de Agosto) e a Escolha da Rainha do Folclore Boliviano. Nesta escolha, 14 escolas e agremiações culturais da comunidade boliviana competem através de desfile, danças e perguntas sobre a cultura do país. As representantes destes grupos são jovens meninas, entre 15 e 20 anos, que carregam consigo a torcida de centenas de pessoas que, animadamente, lotam o auditório principal da Missão Paz.

As relações de gênero no âmbito da Associação são visíveis: enquanto a diretoria é formada por apenas uma mulher, e os membros habilitados e

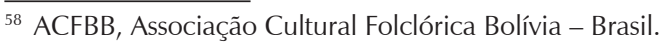


destacados com camisas e crachás oficiais para a organização da Escolha da Rainha sejam também predominantemente homens, são as mulheres e meninas que competem entre si e carregam em seus passos de dança, vestimentas típicas e respostas aos jurados (também de maioria masculina) as esperanças de sua comunidade. São a maioria nas torcidas e são quem, na prática, tornam o espaço e a atividade possíveis.

\section{Considerações Finais}

Neste artigo, buscamos analisar a formação a imigração de haitianos e bolivianos à luz das transformações urbanas na cidade de São Paulo. A reflexão sobre o processo de urbanização da capital paulista nos permitiu compreender como as territorialidades migrantes são historicamente datadas: bairros que "já foram" italianos, nordestinos, latino-americanos e agora são haitianos e africanos. Optamos por seguir as pistas espaciais deixadas por imigrantes haitianos e bolivianos em seu processo de inserção laboral e interação sociocultural. Nesses processos, estes e outros grupos imigrantes percorrem um determinado espaço de vida dentro da cidade, alterando a paisagem social urbana e construindo suas próprias territorialidades.

As entrevistas realizadas ao longo do trabalho de campo ${ }^{59}$ permitiram compreender como o processo de produção das territorialidades migrantes é diverso segundo o capital social e os recursos materiais dos grupos migrantes. A análise teórica, por sua vez, permitiu-nos associar a construção dessas territorialidades à lógica de produção do espaço na cidade: embora muitas vezes trabalhem próximos às áreas mais nobres da cidade, é em espaços deteriorados dos anéis central e interior, e também em regiões afastadas no anel periférico, que imigrantes haitianos e bolivianos residem e constroem seu próprio espaço de vida.

Privilegiamos, portanto, apresentar algumas reflexões e descobertas de nossa investigação sobre "qual é a cidade construída pelos imigrantes haitianos e bolivianos em São Paulo". Claro está que essa cidade por eles construída não se cria por geração espontânea, senão que é erguida em terrenos materiais e simbólicos herdados de processos migratórios e de construção de territorialidades anteriores. Igualmente, a cidade construída pelos imigrantes,

${ }^{59}$ Essas entrevistas foram realizados no âmbito da pesquisa de pós-Doutoramento "Espaços da Imigração Haitiana na Metrópole de São Paulo: Condições, remessas e inserção laboral" (CNPq/ PDJ - PUC - SP), realizada por Luís Felipe Aires Magalhães e coordenada pela Profa Drạ Lúcia Maria Machado Bógus. Essa pesquisa, desenvolvida no Observatório das Metrópoles (PUC SP), teve sua primeira etapa de realização entre Março de 2017 e Março de 2018, período no qual foram feitas entrevistas com imigrantes e refugiados de diversas nacionalidades residentes em São Paulo, bem como com representantes de associações migrantes, centros e casas de acolhimento e acompanhamento e pesquisadores e militantes do tema das migrações e do refúgio em São Paulo. 
sua territorialidade, não necessariamente respeita os limites administrativos de uma concepção geográfica de território. Imigrantes haitianos podem residir no Glicério e trabalhar nas obras de ampliação viária na Zona Leste; ou, ainda, ter mobilidades sazonais para o interior do estado ou mesmo para a região Sul do país, para trabalhos temporários a que têm acesso em razão de uma rede social já construída por esses migrantes, a partir de laços de parentesco, amizade e nacionalidade.

Igualmente, as territorialidades migrantes podem frequentemente ocupar um mesmo espaço, no que as hierarquias (étnicas, políticas e econômicas) definem os limites da apropriação do espaço urbano pelos grupos imigrantes.

A cidade construída pelos imigrantes nos pareceu ainda ter como parâmetros a localização dos espaços de acolhimento e de acompanhamento - como no caso dos imigrantes haitianos residentes no Glicério, próximos à Missão Paz - e dos espaços de trabalho, como no caso dos bolivianos que residem no Brás e no Pari, próximo ou no interior das oficinas de costura.

\section{Referências Bibliográficas}

ACFBB, Associação Cultural Folclórica Bolívia - Brasil. Disponível em: <http:// www. boliviacultural.com. br/classificados/products. php? product $=$ ACFBB \%252d-Associa\%E7\%E3o-Folcl\%F3rica-Cultural-Bol\%EDvia-Brasil >.

BAENINGER, Rosana. Fases e faces da migração em São Paulo. Campinas: Núcleo de Estudos de População-Nepo/Unicamp, 2012.

BAENINGER, Rosana. Migração Transnacional: elementos teóricos para o debate. In BAENINGER, Rosana et alii (org.). Imigração Haitiana no Brasil. Jundiaí: Paco Editoral, 2016.

BAENINGER, Rosana. Migrações Sul-Sul. In BAENINGER, Rosana; BÓGUS, Lúcia Machado; MOREIRA, Júlia Bertino et alii (orgs.). Migrações Sul-Sul. 2a edição. Campinas, SP: Núcleo de Estudos de População "Elza Berquó" - Nepo/Unicamp, 2018.

BÓGUS, Lúcia Maria Machado; MOZINE, Viviane. Imigração e Refúgio no Brasil Contemporâneo: 1930-2012. In CUTTI, Dirceu et alii (orgs.). Migração, Trabalho e Cidadania. São Paulo: EDUC, 2016.

BONACICH, Edna. A Theory Of Ethnic Antagonism. The Split Labor Market. American Sociological Review, v. 37, 1973, p. 547-559.

BOURDIEU, Pierre. Efeitos do Lugar. A miséria do mundo. Petrópolis: Vozes, 1997. BRANDÃO, Carlos; MACIEL, Cláudio; MACEDO, Fernando Cézar de. Economia, Urbanização e Novas Territorialidades no Desenvolvimento de São Paulo. Travessia, Revista do Migrante, São Paulo: CEM, Ano XIX, n. 54, Jan./Abr. 2006, p. 39-44.

BRITO, Fausto. As Migrações Internas no Brasil: Um ensaio sobre os desafios teóricos recentes. Texto Para Discussão, n. 66. Belo Horizonte: UFMG/Cedeplar, 2009. 
BRUNA, Gilda Collet. Urbanização e Regularização de Loteamentos e Habitações. In BÓGUS, Lúcia; RAPOSO, Isabel; PASTERNAK, Suzana (orgs.). Da Irregularidade Fundiária Urbana à Regularização: Análise Comparativa Portugal - Brasil. São Paulo: EDUC, 2010, p. 359-380.

CANALES, Alejandro. E Pur Si Muove. Elementos para una teoría de las migraciones en el capitalismo global. Guadalajara: M.A Porrúa Y Universidad de Guadalajara, 2015.

CASTLES, Stephen; MILLER, Mark. The Age of Migration. International Population Movements in the Modern World. London: Palgrave, 2003.

CEPAL. La actual crisis financiera internacional y sus efectos en América Latina y el Caribe. 2009. Disponível em: <http://www.cepal.org/publicaciones/ xml/0/35390/2009-25-Thecurrentinternationalfinancialcrisis_ESPANOL-WEB. PDF>. Acesso em: 02.2015.

COURGEAU, Daniel. Nuevos Enfoques para Medir la Movilidad Espacial Interna de la Poblácion. Revista Notas de Población, n. 50, 1980, p. 55-74.

COVARRUBIAS, Humberto Márquez. Desarrollo y Migración: Una lectura desde la Economia Política. Revista Migración y Desarrollo, n. 14, primeiro semestre de 2010, p. 59-87.

DOMENACH, Hervé. Sobre la "Migratología". REMI, Revista Europea de Migrações Internacionais, v. XII, 1996, p. 101-118.

FERNANDES, Duval; CASTRO, Maria da Consolação G. de. Migração e Crise: O retorno dos imigrantes brasileiros em Portugal. REMHU, Revista Interdisciplinar da Mobilidade Humana, Brasília, v. 21, n. 41, jul./dez. 2013, p. 99-116.

GUARNIZO, Luis Eduardo et alii. Assimilation and Transnationalism: Determinants of Transnational Political Action among Contemporary Migrants. The American Journal of Sociology, v. 108, n. 6, 2003, p. 1211-48.

HABA, Juan de la; SANTAMARÍA, Enrique. Migraciones, Espacios Urbanos y Hospitalidad. Travessia, Revista do Migrante, São Paulo: CEM, Ano XIX, n. 54, Jan./Abr. 2006, p. 12-17.

HARVEY, David. Cidades Rebeldes: Do direito à cidade à revolução urbana. São Paulo: Martins Fontes, 2014.

MAGALHÃES, Luís Felipe Aires. A imigração haitiana em Santa Catarina: perfil sociodemográfico do fluxo, contradições da inserção laboral e dependência de remessas no Haiti. Tese (doutorado) - Campinas, SP: Universidade Estadual de Campinas, Instituto de Filosofia e Ciências Humanas, 2017.

MAGALHÃES, Luís Felipe Aires; BÓGUS, Lúcia; BAENINGER, Rosana. Migrantes e Refugiados Sul - Sul na Cidade de São Paulo: Trabalho e espacialidades. In BAENINGER, Rosana; BÓGUS, Lúcia Machado; MOREIRA, Júlia Bertino et alii (orgs.). Migrações Sul-Sul. Campinas, SP: Núcleo de Estudos de População "Elza Berquó" - Nepo/Unicamp, 2018 (2ª edição).

MARX, Karl. O capital: Crítica da economia política. Livro I e II. São Paulo: Difel, 1988 [1867]. 
Organização Internacional do Trabalho (OIT). Inserção Laboral de Imigrantes Internacionais: Transitando entre a economia formal e informal no município de São Paulo. Brasil, 2017.

PACHECO, Carlos Américo. Fragmentação da Nação. Campinas: Instituto de Economia da Unicamp, 1998.

PACífICO, Andrea Maria Calazans Pacheco. O Capital Social dos Refugiados: Bagagem cultural versus políticas públicas. Tese de Doutorado em Ciências Sociais. Pontifícia Universidade Católica de São Paulo (PUC - SP), 2008.

PASTERNAK, Suzana. Evolução Espacial dos Loteamentos Irregulares em São Paulo. In BÓGUS, Lúcia; RAPOSO, Isabel; PASTERNAK, Suzana (orgs.). Da Irregularidade Fundiária Urbana à Regularização: Análise Comparativa Portugal Brasil. São Paulo: Educ, 2010, p. 381-416.

PASTERNAK, Suzana; BÓGUS, Lúcia. São Paulo: Transformações na Ordem Urbana. Rio de Janeiro: Letra Capital, 2015.

PERES, Roberta. Imigração e Gênero: As mulheres haitianas no Brasil. In BAENINGER, Rosana et alii (orgs.). Imigração Haitiana no Brasil. Jundiaí: Paco Editoral, 2016.

PORTES, Alejandro; LANDOLT, Patricia. The downside of social capital. The American Prospect, n. 26, 1996, p. 18-22.

SASSEN, Saskia. As cidades na economia mundial. São Paulo: Studio Nobel, 1998.

SILVA, Camila Rodrigues da. Migração de Venezuelanos para São Paulo: Reflexões iniciais a partir de uma análise qualitativa. In BAENINGER, Rosana; BÓGUS, Lúcia Machado; MOREIRA, Júlia Bertino et alii (orgs.). Migrações Sul-Sul. Campinas, SP: Núcleo de Estudos de População "Elza Berquó" - Nepo/Unicamp, 2018 (2ª edição).

SILVA, Sidney Antônio da. Bolivianos em São Paulo: entre o sonho e a realidade. Revista Estudos Avançados USP, v. 20, n. 57, 2006, p. 157-170.

SILVA, Sidney Antônio da. Uma Face Desconhecida da Metrópole: Os bolivianos em São Paulo. Travessia, Revista do Migrante, ano VIII, n. 23, Set./Dez. 1995, p. 14-19.

SINCRE - Sistema Nacional de Cadastro de Registro de Estrangeiro. Polícia Federal. 2015.

SINGER, Paul. Economia Política da Urbanização. São Paulo: Brasiliense, 1995.

TASCHNER, Suzana Pasternak; BÓGUS, Lucia Maria Machado. A cidade dos anéis: São Paulo. In RIBEIRO, Luiz Cesar de Queiroz (org.). O futuro das metrópoles: desigualdades e governabilidade. Rio de Janeiro: Editora Revan, 2000.

THOMAZ, Omar Ribeiro. O terremoto no Haiti, o mundo dos brancos e o lougawou. Revista Novos Estudos CEBRAP, n. 86, mar. 2010, p. 23-39.

VÉRAS, Maura Pardini Bicudo. DiverCidade: Territórios estrangeiros como topografia da alteridade em São Paulo. São Paulo: Educ, 2003. 
VÉRAS, Maura Pardini Bicudo. Novos Nômades Urbanos na Cidade Contemporânea: Desigualdade e exclusão sociais em São Paulo. In SILVA, Ana Amélia da; CHAIA, Miguel (orgs.). Sociedade, Cultura e Política: Ensaios críticos. São Paulo: Educ, 2004.

WALDINGER, Roger. The Ethnic Enclave Debate Revisited. International Journal of Urban and Regional Research, v. 17, n. 3, 1993, p. 444-452.

Recebido para a publicação em 31.01.2018

Aceito para publicação em 05.03.2018 Received for publication in January 315t, 2018 Accepted for publication in March 05 ${ }^{\text {th }}, 2018$

ISSN impresso 1980-8585

ISSN eletrônico 2237-9843

http://dx.doi.org/10.1590/1980-85852503880005205 